\title{
In vitro Model for Cryptosporidium parvum Infection
}

\author{
Ahmed MS Bayoumy ${ }^{1}$ MD, Tarek KZaalouk ${ }^{1, *}$,MD Mohammed S El Faramawy ${ }^{1}$ MD, \\ Ahmed S Elagmy ${ }^{1}$ MB BCh
}

\section{*Corresponding Author: Tarek K Zaalouk tkzaalouk@gmail.com}

Received for publication December 11, 2019; Accepted January 1, 2020; Published on line January 22, 2020

\section{Copyright 2020 The Authors published by Al-Azhar University, Faculty of Medicine, Cairo, Egypt. All rights reserved. This an open- access article distributed under the legal terms, where it is permissible to download and share the work provided it is properly cited. The work cannot be changed in anyway or used commercially.}

doi:10.21608/aimj.2020.22249.1064

${ }^{I}$ Medical Parasitology Department, Faculty of Medicine, Al-Azhar University, Cairo, Egypt.

\begin{abstract}
Background: The in vitro culture system of C. parvum has been investigated using numerous cell lines that support the growth of different stages of the parasite which is less expensive and more convenient for the study of host-parasite interactions than in vivo models .

Objective of the study: to evaluate in vitro models of C. parvum and to establish an in vitro culture system for further research studies .

Material and Methods: Confluent HT-29 Human Colorectal Adenocarcinoma cell monolayers were infected with 4 x105 viable C. parvum oocysts, suspended in $200 \square 1$ cell culture medium (DMEM). Cells were then incubated for 2 hours at $37^{\circ} \mathrm{C}$. Cell monolayers that grow on 13 $\mathrm{mm}$ glass coverslips were washed twice with PBS and fixed in methanol for $1 \mathrm{~min}$, stained with $10 \%$ Giemsa at different periods $(6,24,48$ and 72 h) and then mounted on glass slides. The parasites were counted, and the obtained data were statistically analyzed

Results: It was found that the HT-29 cell line supports the in vitro cultivation of $\mathrm{C}$. parvum. The maximum numbers of parasites were obtained by $6 \mathrm{~h}$ and $24 \mathrm{~h}$ post-infection. Only immature stages were observed in the cell line after $6 \mathrm{~h}$ of infection. However, there were many immature and mature asexual stages in the cell monolayer 24 and 48 post infection. The maximum numbers of parasites were counted in cell monolayer infected by $4 \times 105$ oocysts .

Conclusion: It was concluded that the HT-29 cell line supports the in vitro cultivation of $\mathrm{C}$. parvum protozoan parasite .

Keywords: HT-29; Human; Adenocarcinoma cell line, C. parvum; Oocysts; In vitro culture.
\end{abstract}

Disclosure: the authors have no financial interest to declare in relation to the content of this article. The article processing charge was paid for by the authors.

Authorship: all authors have contributed to the article.

\section{INTRODUCTION}

Cryptosporidium is a genus of protozoan parasites which is a part of the coccidia group, from the phylum Apicomplexa, which also includes Isospora and Cyclospora. ${ }^{1}$ until the mid-1990s, several species of Cryptosporidium were described depending on morphology and host specificity. C. parvum, C. muris, C. felis and C. wrairi were identified as species that infect mammals. C. parvum was the primary species that have been isolated from infected humans ${ }^{2,3}$ and cross-transmission studies indicated that C. parvum isolates can be transmitted from humans to animals and between different animals. ${ }^{4}$

C. parvum is an intracellular parasite that infects the microvillous region of epithelial cells in the digestive tract of vertebrates, resulting in watery diarrhea.

In immunosuppressed individuals, the symptoms are particularly severe and can be fatal. ${ }^{5,6}$ The parasite is primarily spread through the fecal-oral route, often through contaminated water. ${ }^{7,8}$ The life cycle of Cparvum begins with the ingestion of oocysts by the host. In the intestine, four sporozoites are excysted, which then infect epithelial cells and initiate asexual development. They become internalized and undergo merogony, in which eight merozoites are produced. Merozoites from this type I meront can either produce another type I or may develop as a type II meront with four merozoites. The four merozoites released from the type II merogony give rise to the sexual developmental stages, the micro and macrogamonts. The release of microgametes, and their union with macrogametes, gives rise to the zygote, which, after two asexual divisions, forms the environmentally resistant oocyst containing four sporozoites while still within the host cell. ${ }^{9}$

Environmentally robust oocysts are shed by infected hosts into the environment. These oocysts can survive the adverse conditions on the environment for months until it is ingested by a new suitable host. In the new host, the life cycle starts again, and multiplication occurs, using resources of the host. ${ }^{9}$

Methods for the in vitro cultivation of the parasite were advanced significantly in the recent years. The parasite can develop in a variety of epithelial cell lines including human enterocyte lines (e.g. Caco 2, HT-29) $)^{10,11}$ and a similar murine cell line (CMT-93) ${ }^{12}$ Parasite development is limited, but in vitro, growth is enough to support a variety of research studies. Routine methods for parasite preparation and cell culture infection assays for parasite development have been established, however. C. parvum oocysts can be generated in rodent animal models ${ }^{13}$ but largescale production is generally accomplished in neonatal livestock, especially bovine calves and goat kids. ${ }^{14}$ Several methods have been described for purification, concentration and surface sterilization of oocysts. ${ }^{15}$ Oocysts generated in animals have 
limited durability, with infectivity markedly diminished within 6-8 weeks for in vitro and in vivo studies. Moreover, in vitro models enable the amplification of parasitic material for further immunological, biochemical and molecular studies. ${ }^{15,16}$ Parasite development in cell culture can be assessed microscopically with a variety of histological stains or immunofluorescence ${ }^{17}$ and by enzyme immunoassay ${ }^{18}$ or PCR assays. ${ }^{19}$

The study aimes to evaluate and validate in vitro models of C. parvum and to establish an in vitro culture system for the parasite for further research studies.

\section{MATERIALS AND METHODS}

All plastic consumables (e.g. flasks, pipettes and tissue culture plates) were purchased from Vacsera Vaccination Centers, Cairo, Egypt.

HT-29: Human Colorectal Adenocarcinoma cell line was obtained from Cell Culture Lap, Faculty of Pharmacy, Al-Azhar University, Cairo. Dulbecco's modified Eagle medium (DMEM), heat-inactivated fetal bovine serum, penicillin-streptomycin, glutamine, nonessential amino acids, phosphatebuffered saline (PBS), trypsin and all other chemicals were obtained from Vacsera Vaccination Centers.

HT-29: Human Colorectal Adenocarcinoma cell lines were grown in DMEM medium supplemented with $10 \%$ heat-inactivated fetal calf serum, $4 \mathrm{mM}$ glutamine, $100 \mathrm{U} / \mathrm{ml}$ penicillin, $100 \mu \mathrm{g} / \mathrm{ml}$ streptomycin and $1 \%$ non-essential amino acids in a $5 \% \mathrm{CO} 2$ and incubated at $37 \mathrm{oC}$. For experiments, trypsinized cells were seeded into 24 - well plastic tissue culture plates with $13 \mathrm{~mm}$ diameter glass coverslips and grow to confluence over 5 days. All experiments were done in triplicate. ${ }^{20}$

C. parvum oocysts were obtained from Theodor Bilharz Research Institute (TBRI) Cairo, Egypt. Before use, oocysts will surface sterilized by suspension in $10 \%$ commercial bleach solution ( $0.55 \%$ sodium hypochlorite) for 10 minutes and subsequently washed 3 times in DMEM before enumeration in a Neubauer hemocytometer. ${ }^{21}$

Confluent cell monolayers were infected with 4X105 viable C. parvum oocysts suspended in $200 \mu \mathrm{l}$ cell culture medium. Cells were then incubated for 2 hours at $37^{\circ} \mathrm{C}$ to allow excystation and host cell invasion to occur. Following this period, unattached parasites and oocyst debris were removed by washing twice with the medium.

Wells were subsequently filled with fresh medium and incubated at $37^{\circ} \mathrm{C}$ for the stated time..$^{21}$

Cell monolayers that grown on $13 \mathrm{~mm}$ glass coverslips were washed twice with PBS to remove any traces of medium and fixed in methanol for 1 min, stained with $10 \%$ Giemsa (diluted in PBS, $\mathrm{pH}$ 7.2) for $2 \mathrm{~h}$, washed in de-ionized water and then mounted on glass slides. Using a Zeiss Axioplan microscope at X1000 magnification with oilimmersion the parasites were counted in 20 fields across the diameter of the coverslip starting from the periphery. ${ }^{21}$ The obtained data were expressed as means \pm SD. Significance analysis was carried out using a two-tailed Student's t-test for unpaired means.

\section{RESULTS}

In vitro development of c. parvum in intestinal epithelial cells showed that; confluent monolayers of HT-29 to which C. parvum oocysts were added, fixed and stained with Giemsa at different periods $(6,24$, 48 and 72 hours) after incubation at $37 \mathrm{oC}$. The tested cell line (HT-29) was found to support C. parvum growth in vitro. (Figure 1)

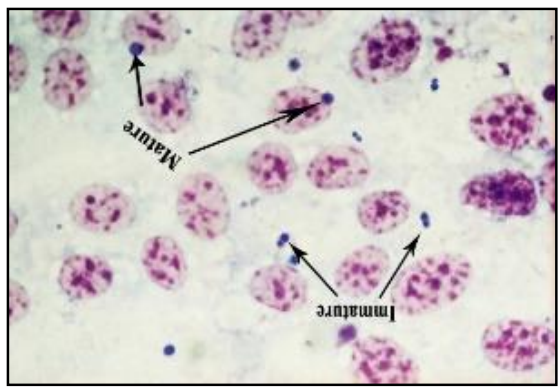

Fig. 1: C. parvum development in HT-29 cells. The monolayers were grown on glass coverslips in 24- wells plate, infected with $4 \times 105$ oocysts and stained with Giemsa. After $24 \mathrm{~h}$ of infection, both immature and mature asexual stages can be identified clearly by microscopy. (X 1000).

The maximal number of intracellular parasites was obtained at 6-24 hs $(127 \pm 11$ and $159 \pm 13$ parasite/20 fields respectively), but the number of parasites decreased at $48 \mathrm{~h}(91 \pm 10$ parasite/20 fields $)$ and $72 \mathrm{~h}(39 \pm 5$ parasite/20 fields) of infection. (Figure 2)

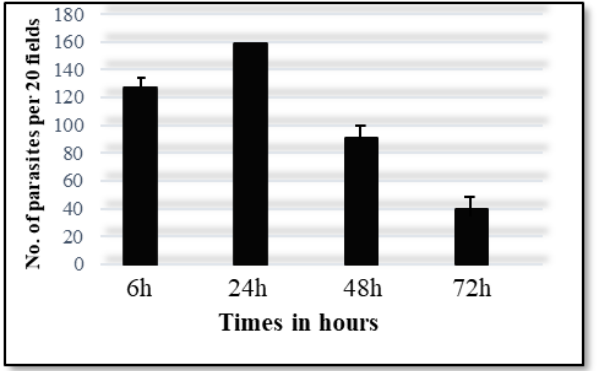

Fig. 2: Pattern of $C$. parvum infection in HT-29 cells. The maximal number of parasites was obtained 6-24 h postinfection with no significant difference in infection observed between 6 and 24h incubation periods $(p>0.05)$. Fewer parasites were obtained at $48 h(p<0.02)$ and $72 \mathrm{~h}(\mathrm{p}<0.008)$ compared with $24 \mathrm{~h}$.

Identification of C. parvum asexual stages in infected cell monolayers. Study noted that after $6 \mathrm{~h}$ only immature stages were seen but at $24 \mathrm{~h}$ immature and many mature asexual stages could be viewed and by $48 \mathrm{~h}$ the number of both immature and asexual mature stages was decreased. (Figure $3 \mathrm{a}, \mathrm{b}$ and c) 
Infection of cell monolayers by different concentrations of oocysts. The maximal number of parasites was obtained by using $4 \times 105$ oocysts with no significant difference in infection observed between $4 \times 105$ and $1 \times 105$ oocysts $(p>0.05)$. Fewer parasites were obtained when used $2 \times 104$ compared with $1 \times 105(\mathrm{p}<0.02)$ and $4 \times 105(\mathrm{p}<0.008)$ compared with 24h. (Figure 4)

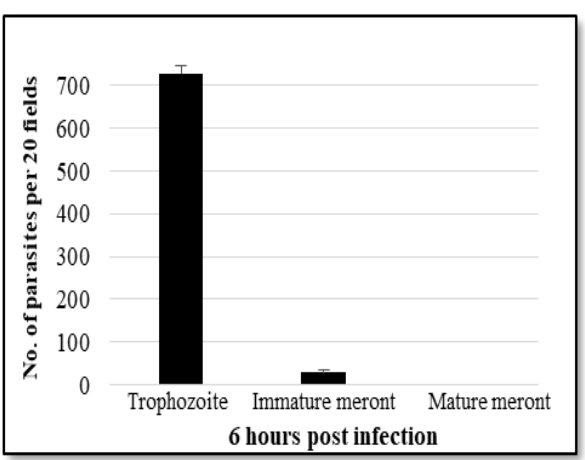

Fig. 3a

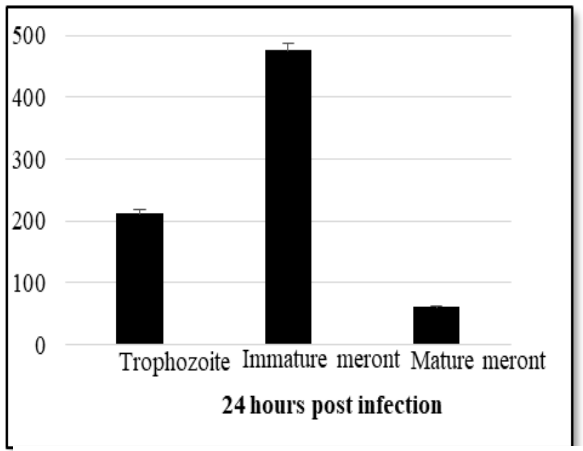

Fig. 3b

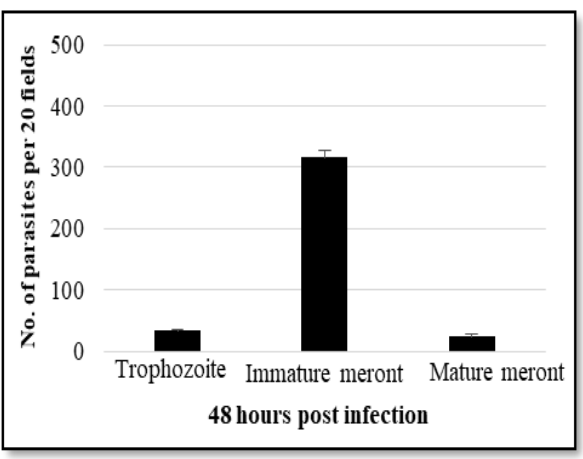

Fig. 3c

Fig. (3 a-c): Identification of immature and mature asexual stages in the cell line. Microscopic examination of Giemsa stained HT-29 monolayer $6 \mathrm{~h}$ post-infection reveals many immature stages, but no mature parasite could be detected (Fig. 3a). Many immature and mature asexual stages of Cparvum were observed in infected cells 24 hours postinfection (Fig. 3b). After 48 hours of infection, there was significant reduction in the number of immature and asexual mature stages of the parasite (Fig. 3c).

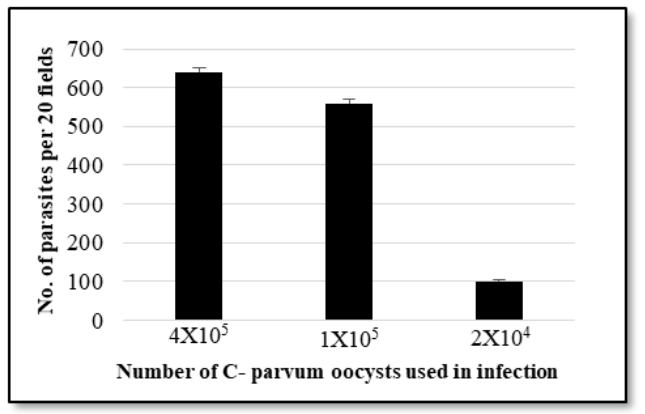

Medical

Parasitology

Fig. 4: C. parvum infection in HT-29 cells using variant numbers of viable oocysts. Infection of cell monolayer by using $4 \times 105$ oocysts produced the highest numbers of parasites with no significant difference in infection observed between $4 \times 105$ and $1 \times 105$ oocysts ( $p>0.05$ ). Fewer parasites were obtained when used 2x104 compared with $1 \times 105$ (p $<0.02)$ and $4 \times 105(\mathrm{p}<0.008)$.

\section{DISCUSSION}

A key goal of this study was to confirm the development of C. parvum in the intestinal epithelial cell line. The present study was shown that $\mathrm{C}$. parvum can invade and develop within HT-29. However, only asexual development was predominantly observed with gametes being observed only occasionally. Complete development of C. parvum in vitro has been previously described 1, 5 and parasite growth was maintained for up to 25 days by multiple sub-culturing. It appears that adjustment of $\mathrm{pH}(7.2-7.6)$ by the regular change of culturing media at 2-3 days intervals and adding HEPES buffer may be the key to successful longterm in vitro cultivation of C. parvum. 15 Also, thinwalled oocysts are required to maintain parasite growth by releasing sporozoites that infect new cells (autoinfection) and it was reported that thin-walled oocysts occurred in vitro after the passage of parasite for 12 days. 15 Lack of thick-walled oocysts may reflect the absence of certain enzymes and hormones that are present in vivo or a lack of effective host immune response that may induce the parasite to produce this type of oocysts.15, 22 For my thesis research, this long term cultivation was not essential.

In the present study, the maximal number of parasites was obtained at 6-24h and development had decreased by $48-72 \mathrm{~h}$ of infection. Only immature stages were showed after $6 \mathrm{~h}$ of infection, but many immature and asexual mature stages were observed in the cells 24 and $48 \mathrm{~h}$ post-infection as shown in fig. (3a- c). C. parvum developmental stages were easily identified by Giemsa staining in HT-29 cells. Interestingly, infection of cell monolayers by different concentrations of C. parvum oocyst reveals that the maximal number of parasites was obtained by using $4 \times 105$ oocysts with no significant difference in infection observed between $4 \times 105$ and $1 \times 105$ oocysts. Taken together, these results recommend the use of HT-29 cells to support the study of C. parvum development in vitro. 
Having demonstrated that C. parvum grows in the HT-29 cell line, further investigation of parasite interactions with host cells was possible using these in vitro models of infections.

\section{CONCLUSION}

It was concluded that the HT-29 cell line supports the in vitro cultivation of C. parvum protozoan parasite.

\section{REFERENCES}

1. Janssen B, and Snowden J. Cryptosporidiosis. Stat Pearls (Internet). Treasure Island (FL): Stat Pearls Publishing, 2018. Available at: https://www.ncbi.nlm.nih.gov/books/NBK448085/ Accessed on October 27, 2019.

2. Casemore D, Wright $\mathrm{S}$ and Coop R. Cryptosporidiosis, Human and animal epidemiology. In: Fayer R (ed). Cryptosporidium and cryptosporidiosis. CRC Press, Boca Raton, USA. 1997; pp: 65-92.

3. Fayer R, Morgan $U$ and Upton SJ Cryptosporidium as a parasitic zoonotic. Int $\mathbf{J}$ Parasitol. 2000; 30:1305-1321.

4. Medema G, Deere D, Teunis P, et al. WHO Guidelines for Drinking Water Quality Cryptosporidium. EHC Cryptosporidium draft. 2006; 2: 24-26.

5. Scallan E, Hoekstra RM, Angulo FJ, et al Food-borne illness acquired in the United States major pathogens. Emerg Infect Dis. 2011; 17(1):7-15.

6. Kotloff KL. The burden and etiology of diarrheal illness in developing countries. Pediatr Clin North Am. 2017; 64(4): 799-814.

7. Coulibaly ND and Yameogo KR. Prevalence and control of zoonotic diseases: Collaboration between public health workers and veterinarians in Burkina Faso. Acta Trop. 2000; 76: 53-57.

8. Fathy MM, Abdelrazek NM, Hassan FA, et al. Molecular seroprevalence of Cryptosporidium in Egyptian children and evaluation of three diagnostic methods. Indian Pediatr. 2014; 5(9):727-729.

9. Tzipori S and Griffiths J K. Natural history and biology of Cryptosporidium parvum. $A d v$ Parasitol. 1998; 40: 5-36.

10. Aji $T$, Flanigan $T$, Marshall $R$, et al. Ultrastructural study of asexual development of Cryptosporidium parvum in a human intestinal cell line. J Protozool. 1991; 38: 82S-84S.

11. Buraud M, Forget E, Favennec L, et al. Sexual stage development of Cryptosporidium in the Caco-2 cell line. Infect Immun. 1991; 59: 4610-4613.

12. Lean IS, McDonald SA, Bajaj-Elliott M, et al Interleukin-4 and transforming growth factorbeta have opposing regulatory effects on gamma interferon-mediated inhibition of Cryptosporidium parvum reproduction. Infect Immun. 2003; 71: 4580-4585.
13. Petry F, Robinson HA and McDonald V. Murine infection model for maintenance and amplification of Cryptosporidium parvum oocysts. J Clin Microbiol. 1995; 33, 19221924.

14. Arrowood MJ and Donaldson K. Improved purification methods for calf-derived Cryptosporidium parvum oocysts using discontinuous sucrose and cesium chloride gradients. J Eukaryot Microbiol. 1996; 43(5):89-93.

15. Arrowood MJ. In vitro cultivation of Cryptosporidium species. Clin Microbiol Rev. 2002; 15: 390-400.

16. Petry F. Laboratory diagnosis of Cryptosporidium parvum infection. Contrib Microbiol. 2000; 6: 33-49.

17. Alfa Cisse O, Ouattara A, Thellier M, et al. Evaluation of an immunofluorescentantibody test using monoclonal antibodies directed against Enterocytozoon bieneusi and Encephalitozoon intestinalis for diagnosis of intestinal microsporidiosis in Bamako (Mali). J Clin Microbiol. 2002; 40: 1715-1718.

18. You X, Arrowood MJ, Lejkowski M, et al. In vitro evaluation of anti cryptosporidial agents using MDCK cell culture and chemiluminescence immunoassay. J Eukaryot Microbiol. 1996; 43: 85S -87S.

19. Rochelle PA, Ferguson DM, Handojo TJ, De Leon $\mathrm{R}$, et al. Development of a rapid detection procedure for Cryptosporidium, using in vitro cell culture combined with PCR. J Eukaryot Microbiol. 1996; 43: 71S$72 \mathrm{~S}$.

20. Natoli A, Cabeza A, De La Torre AG, et al. Colloidal processing of microporous $\mathrm{TiO} 2$ materials for photocatalytic water treatment. J Am Ceramic Soc. 2012; 95: 502-508.

21. Pollok RC, Farthing MJ, Bajaj-Elliott M, et al. Interferon-gamma induces enterocyte resistance against infection by the intracellular pathogen Cryptosporidium parvum. Gastroenterol. 2001; 120 (1):99107. 